\title{
Articulo
}

\section{Técnica Espiral de Valoración Rápida de la Tomografia de Cráneo}

\author{
Dr. Juan Ignacio Padilla Cuadra1 \\ 1. Vicedecano de Medicina, Universidad de Iberoamérica \\ Correspondencia a: revistamedicina@unibe.ac.cr
}

\section{Resumen}

El análisis profundo de la tomografía de cráneo es competencia de especialistas en radiología, neurología y neurocirugía. Sin embargo, el médico general debe conocer fundamentos para $\mathrm{su}$ interpretación práctica y detectar padecimientos graves que requieren intervención inmediata.

Se propone un método sencillo para ordenar la manera en que visualizan estos estudios y como detectar hallazgos relevantes. Se muestran imágenes características de estos hallazgos para mejorar la habilidad del estudiante en su reconocimiento

\section{Abstract}

Profound interpretation of head tomography is the goal of neuroradiologist and neurosciencias specialist. Even though, the general practitioner must know how to recognize severe anomalies that require inmediate intervention. We propose an easy way to interpret head tommography. Classical images are added to improve the skill of the medical studente to recognize such findings.

\section{Introducción}

Desde su invención la Tomografía Axial Computarizada (TAC) ha venido a revolucionar el estudio mediante imágenes del sistema nervioso central. Aunque la Resonancia Magnética Nuclear (RMN) permite imágenes más precisas anatómicamente, el TAC puede ser realizado en pocos segundos y es de particular utilidad en pacientes graves que no pueden estar desatendidos por mucho tiempo mientras se completa el estudio.

La interpretación profunda del TAC de cráneo compete al radiólogo y a los especialistas de neurología y neurocirugía. No obstante, mediante métodos simples se puede ordenar mentalmente como visualizar un TAC de cráneo y poder identificar lesiones que ameriten una intervención urgente.

\section{Concepto de densidades}

El desarrollo de la tomografía computarizada se atribuye a Cormack y Hounsefield (Figura 1 y 2) quienes recibieron el Premio Nobel 1979 (1). 


\section{(2) MEDICINA}

Figura 1. Allen M. Cormack

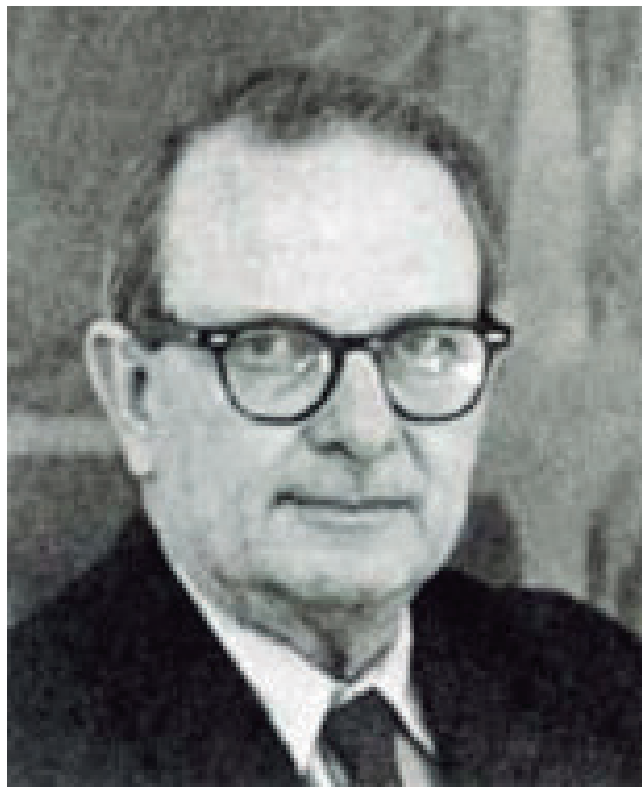

Figura 2. Godfrey Hounsefield

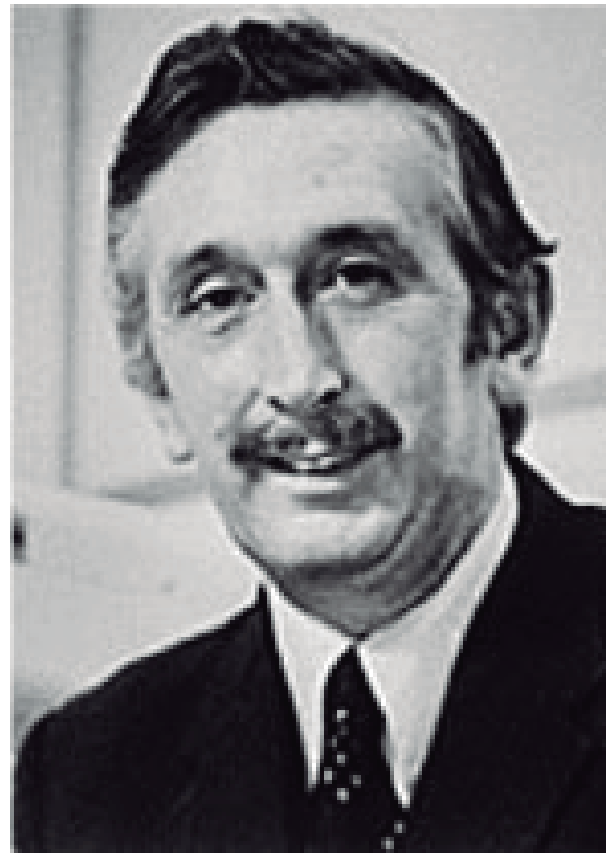

Una de las características de este método deimágenes es que se pueden distinguir los tejidos y sustancias de acuerdo a la densidad de las imágenes que se desarrollan con el tomógrafo. Así, para cada una de estas imágenes se tiene densidades cuantificadas en unidades de Hounsefield, tal como se muestra en el cuadro 1.

\section{TEJIDO}

Aire

$-1000$

Grasa

-100 a -50

Líquido 15

Cefaloraquídeo

Sangre

$30-45$

Músculo

$10-40$

Sustancia Gris

$37-45$

Sustancia Blanca

$20-30$

Medios de Contraste

Hueso Trabecular

$100-300$

Hueso Cortical

700

1000

Cuadro 1. Unidades de Hounsefield para diferentes tipos de sustancias y tejidos Es importante recordar que la densidad de las imágenes en el TAC está relacionada con el tipo de tejido que se visualiza. Así, para cada tejido hay una cuantificación específica de densidad, lo cual se realiza en unidades de Hounsefield.

(Cuadro 1).

En situaciones especiales, es necesario solicitar el estudio tomográfico con medio de contraste (2). En el caso del cráneo esto suele hacerse cuando que quiere visualizar tumores, abscesos, empiemas y por supuestos en caso de estudios vasculares (angiotomografía o Angiotac).

\section{Técnica de la Espiral de 3 Capas}

Una manera práctica y sencilla de valorar una tomografía axial de cráneo es seguir el trazo de una espiral, tal como se muestra a continuación: 


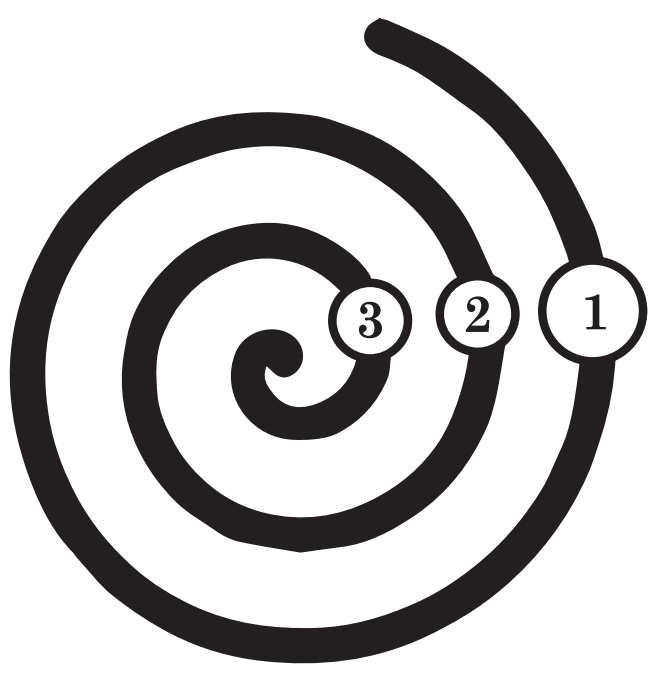

En un plano se valorará la tomografía como si fuera una espiral, primero de afuera hacia adentro. (1..2..3). Además, en una perspectiva tridimensional, se valorará como si esta espiral se extiende en profundidad en la bóveda craneana- Extendiéndose de la parte más superior del cráneo hacia la base.

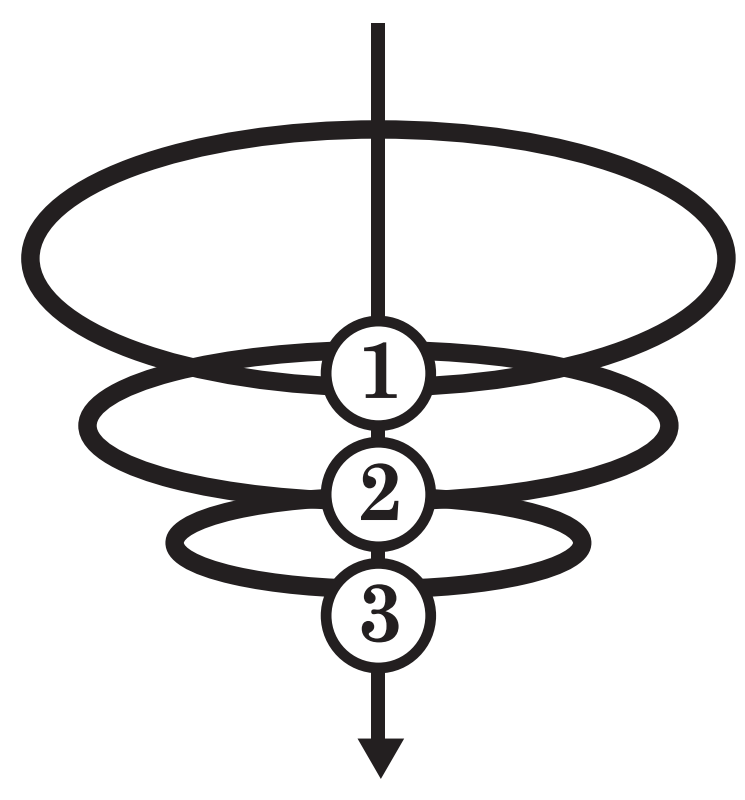

Mediante esta técnica que ordena la valoración del TAC en sentido espiral de afuera hacia adentro, y de arriba hacia abajo, sistemáticamente se detectan anormalidades específicas.

\section{Primera capa:}

En la parte más externa de la espiral, podremos determinar alteraciones de:

- Cuero cabelludo

- Integridad del hueso del cráneo

- Macizo facial y senos paranasales

- Espacio epidural

- Espacio subdural

Veamos algunos ejemplos. En la figura 3, podemos notar en la parte más externa de la imagen, tumefacción del cuero cabelludo, lo cual está en relación a edema posterior a traumatismo (flecha blanca)

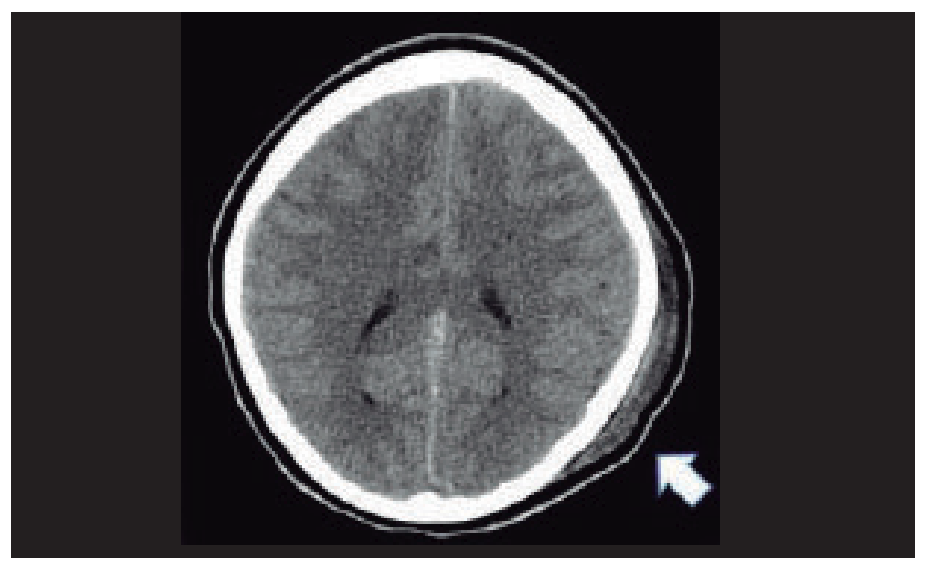

Figura 3.

Tumefacción en cuero cabelludo En la figura 4, puede notarse una pérdida de la continuidad de la bóveda craneana, lo que cual corresponde a fractura craneana.

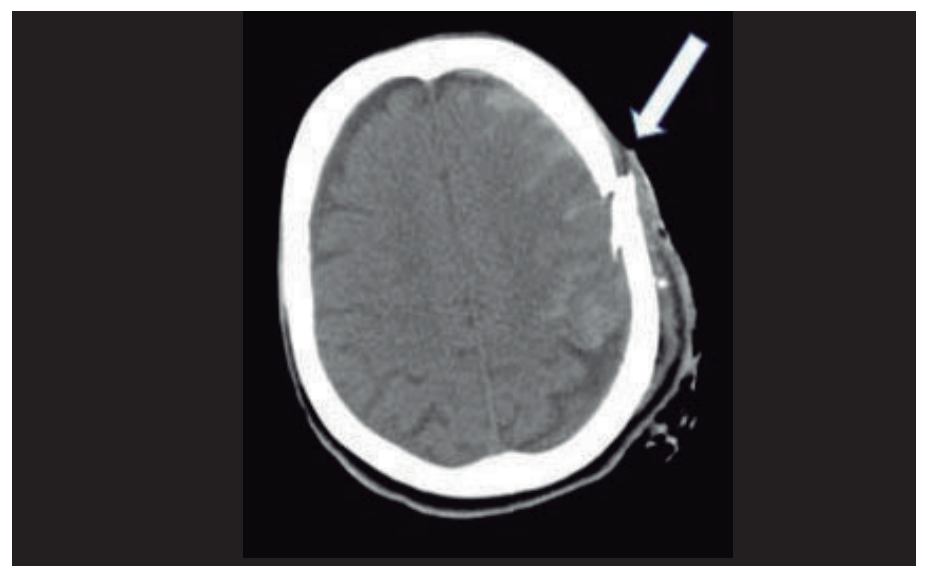

Figura 4. Fractura craneal (flecha) 


\section{(2) MEDICINA}

En la siguiente figura se detalla el defecto descrito.

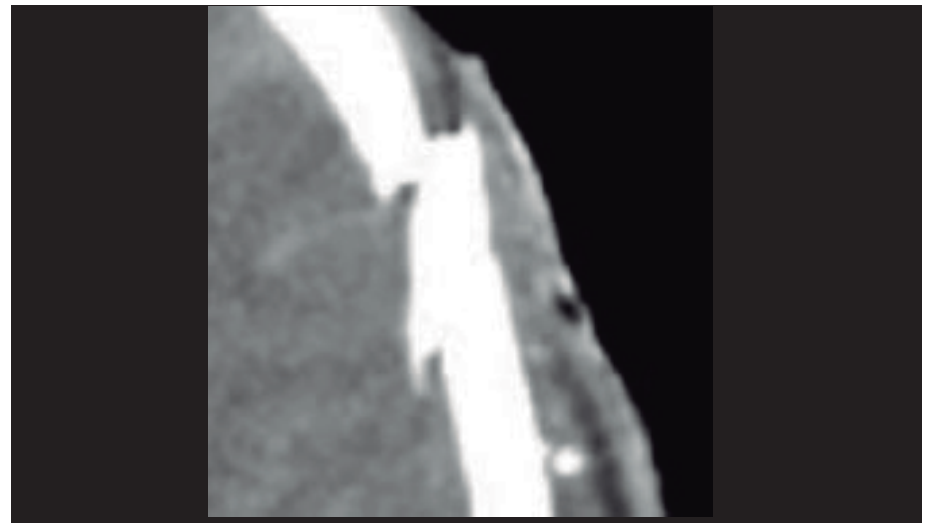

Figura 5. Fractura craneal

Si profundizamos en la espiral entramos a la bóveda y podemos notar, alteraciones del espacio epidural, como es el caso de un hematoma, que posee la morfología característica de un lente biconvexo (Figura 6a). Cuando la imagen corresponde a un lente cóncavo se debe sospechar un hematoma subdural (Figura 6b)

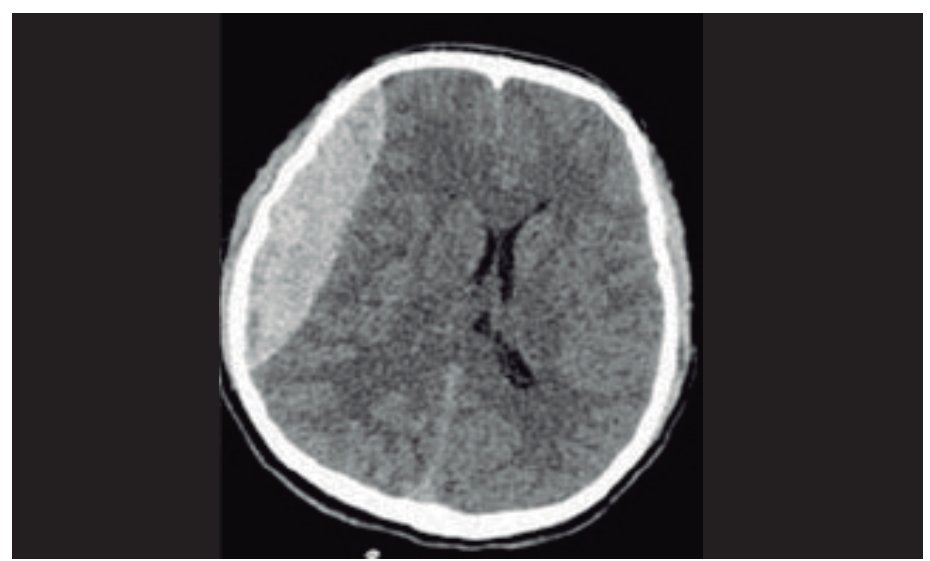

Figura 6a. Hematoma epidural.

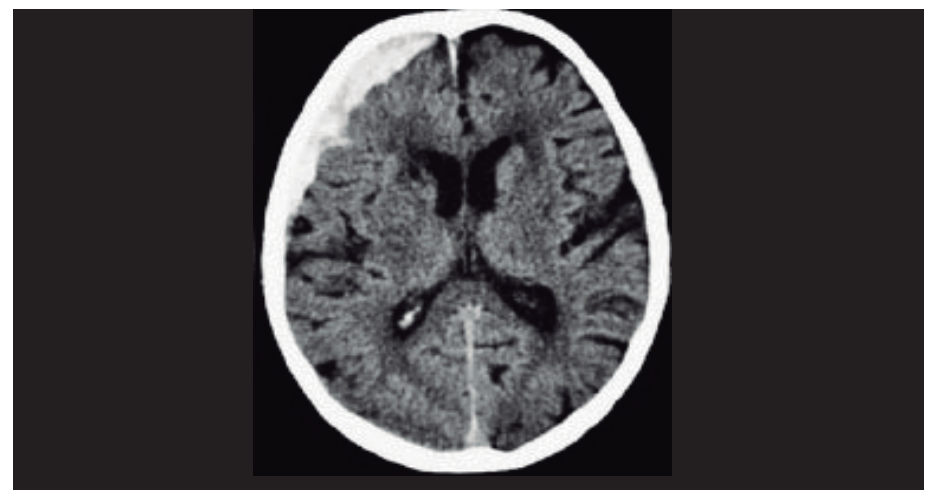

Figura 6b. Hematoma subdural

\section{Segunda Capa:}

Conforme avanzamos hacia el centro, en este segundo paso comenzamos a valorar el parénquima propiamente dicho. Esto nos permite determinar:

- Profundidad de los surcos

- Áreas de hipo o hiperdensidad del parénquima

- Desviaciones de la línea media

En presencia de edema cerebral, un hallazgo común es el aplanamiento de los surcos de la corteza cerebral, tal como muestra la figura 7 .
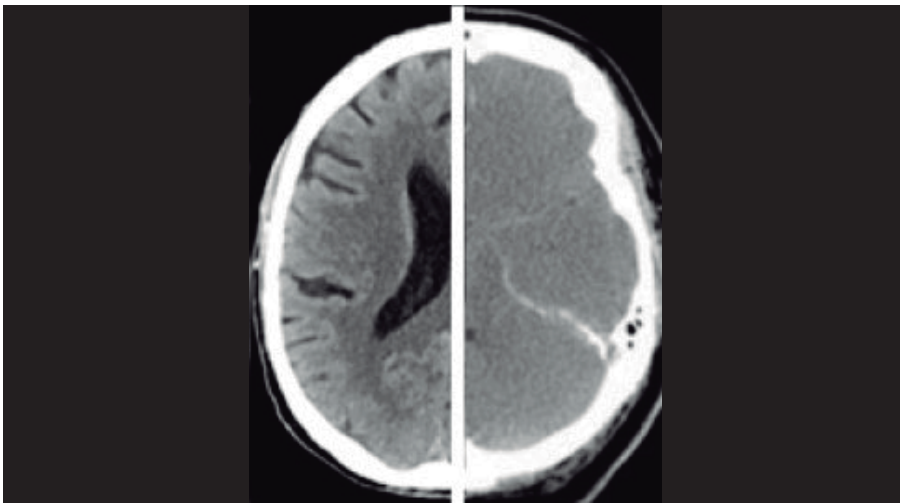

Figura 7. Se contraponen dos tomografías distintas, en la de la izquierda se reconocen lo surco corticales, en la de la derecha se han borrado por efecto del edema cerebral.

La presencia de áreas de hipodensidad parenquimatosa están en relación a infarto.

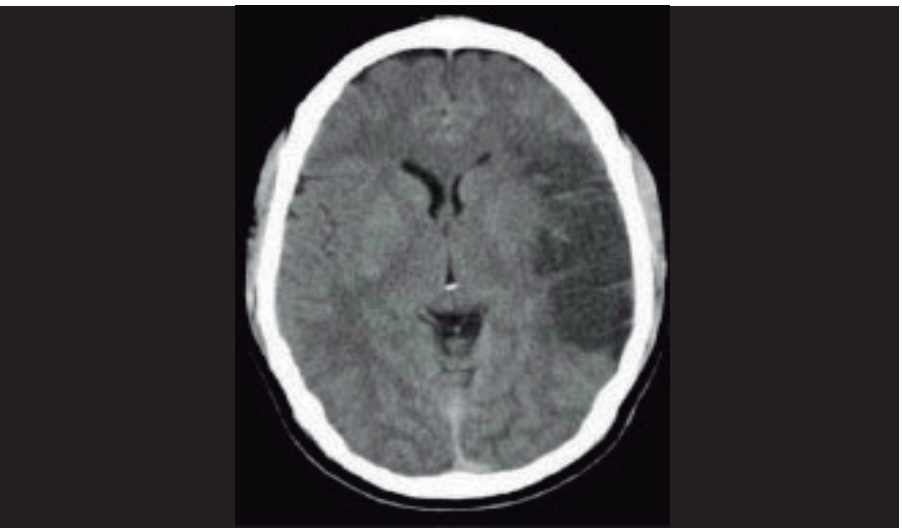

Figura 8. Infarto cerebral de territorio de arterial cerebral media izquierda. 


\section{(2) MEDICINA}

Conforme nos acercamos, al centro, es importante detectar si hay desviaciones de la línea media. Esto indica que hay algo que ejerce un efecto de masa y que desplaza las estructuras(por ejemplo, un hematoma o un tumor) (Figura 9)

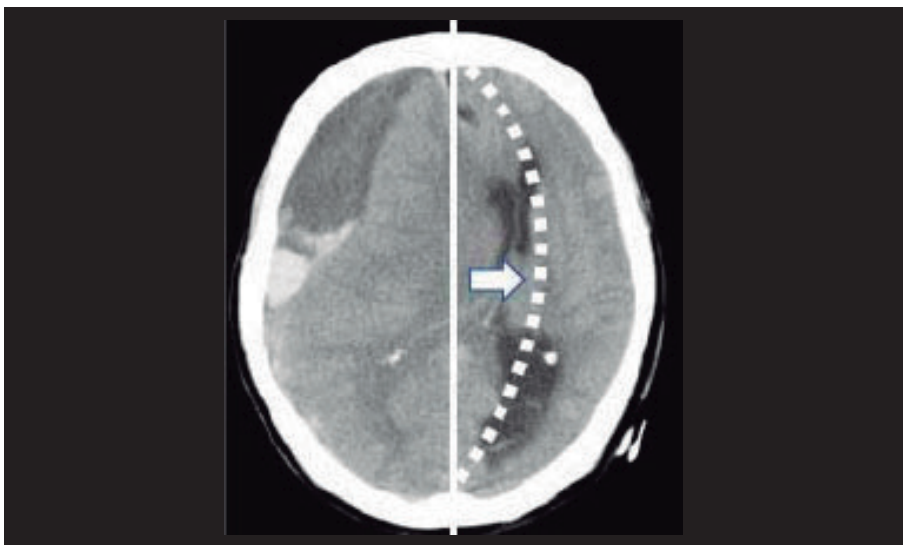

Figura 9. Desviación de la línea media por efecto de hematoma subdural subagudo derecho con sangrado reciente.

\section{Sistema ventricular}

En caso de sospecha de hidrocefalia, la tomografía muestra claramente el aumento de tamaño del sistema ventricular.

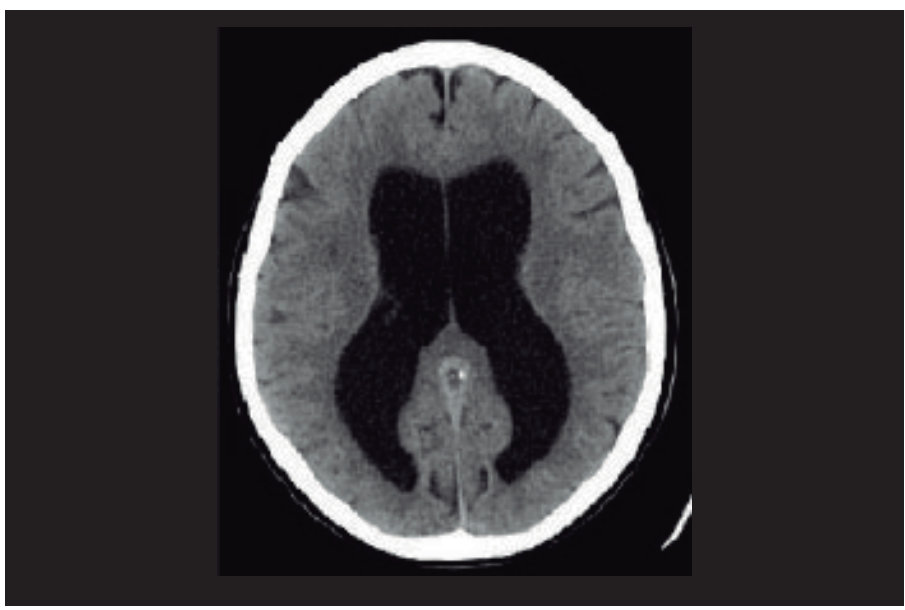

Figura 10. Hidrocefalia que muestra dilatación del sistema ventricular.

Además, es importante, reconocer si el sistema está ocupado por líquido cefalorraquídeo o sangre (figura 11)

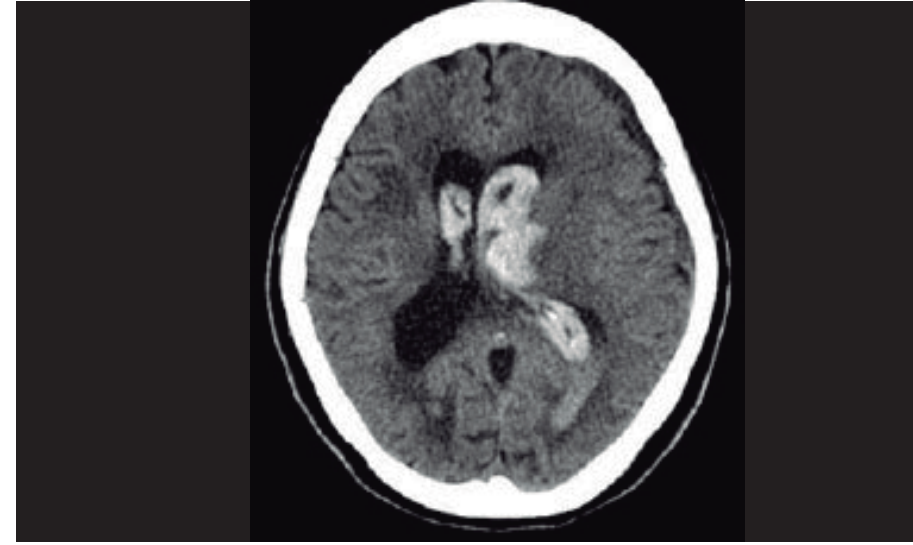

Figura 11. Hemorragia intraventricular extensa.

\section{Tercera capa.}

Hacia el centro del cráneo, debemos concentrarnos en:

- Silla turca

- Cisternas

- Tallo Cerebral

- Base de cráneo

La presencia de una hiperdensidad en el sitio correspondiente a la silla turca, hará sospechar de un adenoma hipofisiario (Figura 12)

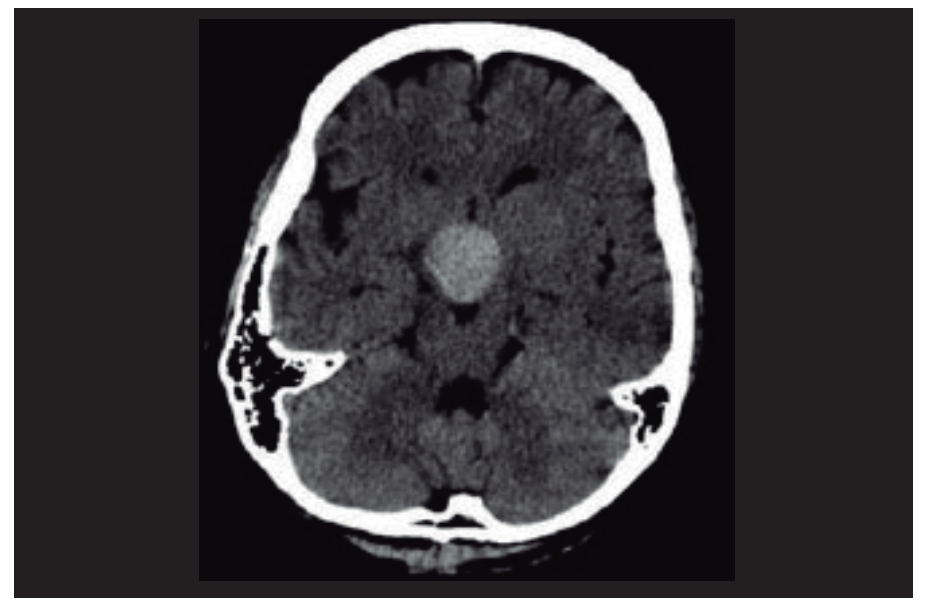

Figura 12. Adenoma hipofisiario Cisternas

Existen espacios en los que se notan acúmulos de líquido cefalorraquídeo denominados cisternas. 


\section{(). MEDICINA}

En condiciones anormales estos espacios pueden estar ocupados por sangre o bien incluso desaparecer como en la hipertensión endocraneana severa. El desvanecimiento (en inglés, effacement) o desaparición de las cisternas es indicador de que hay un aumento de la presión intracraneal severo.

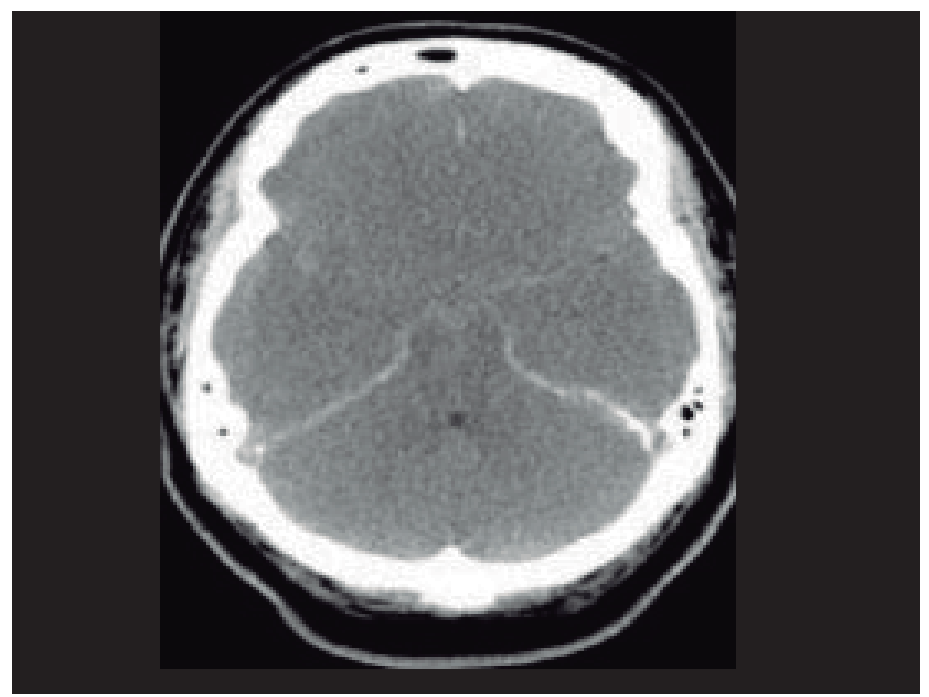

Figura 13. Desvanecimiento de cisternas de la base del cráneo

\section{Tallo cerebral}

Es importante recordar que el TAC es particularmente limitado en la evaluación de patología de la fosa posterior por lo que, en caso de sospecharse lesiones a dicho nivel, ha de considerarse el uso de la resonancia magnética nuclear (RMN).

\section{Base de cráneo}

En las porciones más inferiores de nuestra espiral, corresponde visualizar detenidamente la base del cráneo para detectar anomalías óseas o vasculares.

En la figura 14, se puede notar una pérdida de la continuidad de la base del lado izquierdo que corresponde a una fractura.

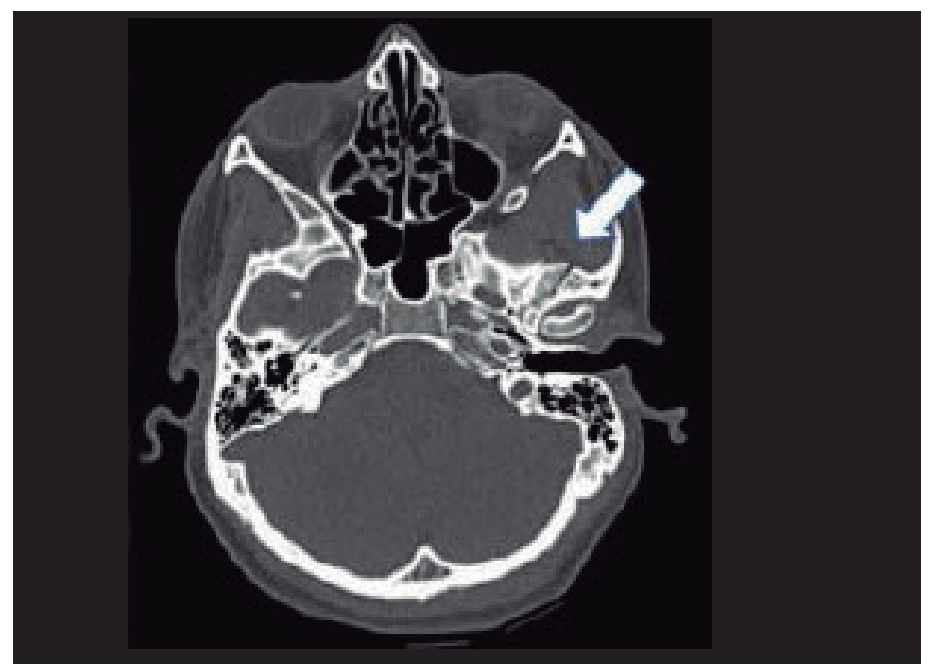

Figura 14a. Línea de fractura en base de cráneo (flecha blanca)

Actualmente, existen herramientas de software que permiten reconstruir en 3 dimensiones estas imágenes y demostrar la fractura y como, en este caso corresponde a la extensión de una fractura de bóveda que llega hasta la base del cráneo (figura 14b).

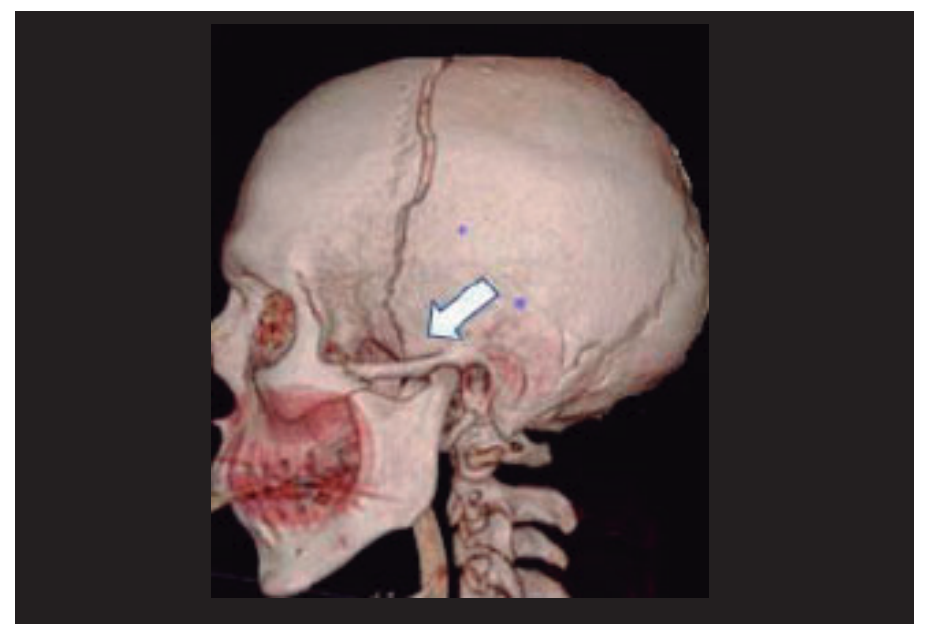

Figura 14b. Línea de fractura se extiende a la base de cráneo (reconstrucción 3-D).

De igual forma, sabiendo que es la base del cráneo que se distribuyen los principales vasos sanguíneos que distribuyen la sangre del 
encéfalo, deben reconocerse alteraciones a dicho nivel como la presencia de un aneurisma.

La figura 15, muestra un sangrado subaracnoideo con extensión a espacio subdural. Si observamos detenidamente, se puede detectar una dilatación que parece vascular y que luego se define como tal en la angio-tomografía (angioTAC).

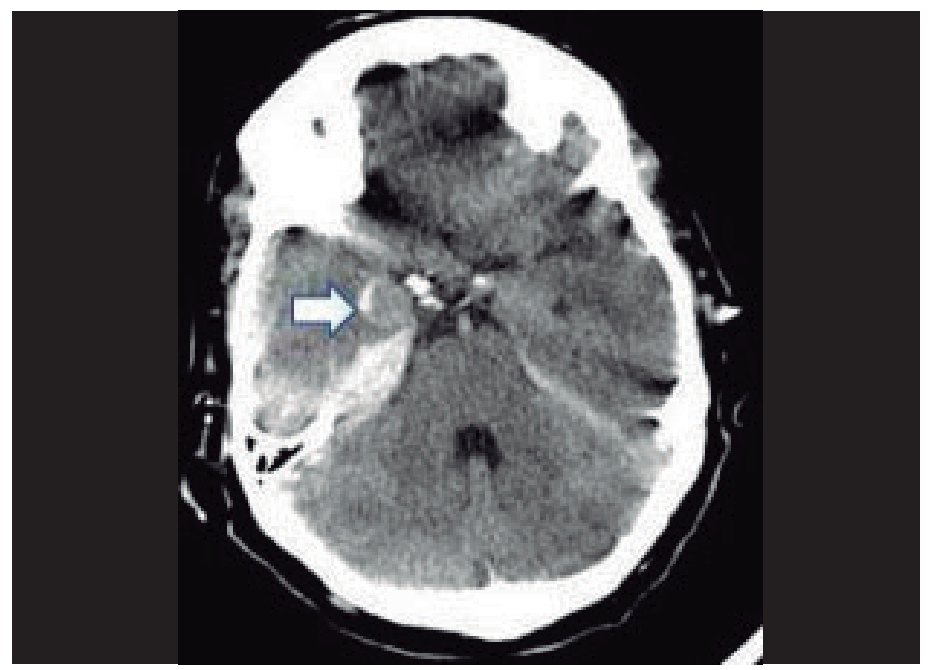

Figura 15. Imagen sugestiva de aneurisma

En casos de hemorragia subaracnoidea, es importante tratar de identificar la causa. En la figura 15 , se nota una imagen que sugiere aneurisma cerebral que luego se confirmó mediante angiografía tomográfica (Figura 16).

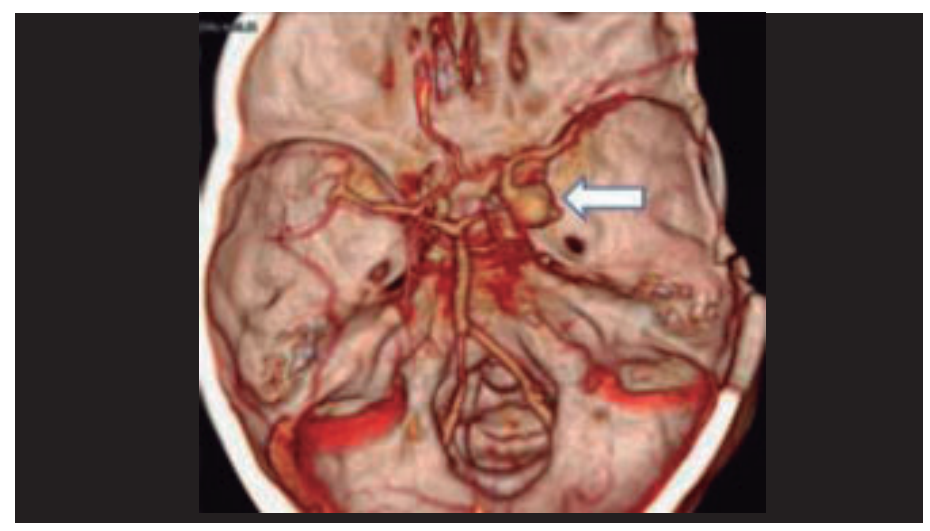

Figura 16. Aneurisma demostrado en reconstrucción 3-D de la angiografía tomográfica.

\section{Conclusión}

El análisis profundo de la tomografía de cráneo es competencia de especialistas en radiología, neurología y neurocirugía. Sin embargo, el médico general debe conocer fundamentos para su interpretación práctica y detectar padecimientos graves que requieren intervención inmediata. Se propone un método sencillo para ordenar la manera en que visualizan estos estudios y como detectar hallazgos relevantes.

\section{Referencias.}

1. Rubin GD. Computed tomography: revolutionizing the practice of medicine for 40 years. Radiology. $2014 \quad$ Nov;273(2 Suppl):S45-74.

2. Rawson JV, Pelletier AL. When to Order a Contrast-Enhanced CT. Am FamPhysician. 2013 Sep 1;88(5):312-6. 